\title{
Analysis on Development Status and Existing Problems for Government Micro Blog
}

\author{
Yuqiang Yang ${ }^{1, a}$, Jiawei Zhao ${ }^{1, b}$, Baodong $\mathrm{Yu}^{1, \mathrm{c}}$, Hang Wang ${ }^{2, \mathrm{~d}}$ \\ ${ }^{1}$ College of Information Science and Technology, Bohai University, Jinzhou, 121013, China \\ ${ }^{2}$ College of Engineering, Bohai University, Jinzhou, 121013, China \\ ayyq8369@163.com, b17257841@qq.com, '589724756@qq.com, dbhdxwanghang@163.com
}

Keywords: government micro blog; development status; existing problems; micro blog management

\begin{abstract}
Government micro blog has become an important platform and channel for the government to communicate with users, listen to the voice of the people. As a new social management model, although it plays a positive role in the "network governance", but at present it does not play its due value. Through in-depth analysis of the development status, summed up the existence of "function and positioning is not clear, regulatory and organizational security deletions, the lack of motivation to maintain long-term, the lack of the necessary marketing tool, development region and application areas is not balanced, content and form stiff" and other problem. To fully understand the current development status of government micro blog and solve the problems, with the participation and concerns of the Internet users to the social public affairs, government micro blog management will penetrate into the actual work of government.
\end{abstract}

\section{Introduction}

With the rapid development of the Internet as the representative of the digital media, micro blog has become an important carrier of network public opinion after the mass media and Internet blog. Although micro blog information capacity is limited to 140 words, but the explosive growth rate, rapid involves all aspects of people's lives. In recent years, in the process of the government frequent "network governance", the micro blog will be a lot of users' individual power to gather into a powerful force, which reflects the advantages of mass media cannot be compared. Government micro blog gradually become the hot spot, the government is widely advocated through the channels of micro blog, "ask government to the people, ask require to the people, and Ask plan at civilian". As the national Internet information office director Wang Chen said, the government micro blog can "expand ties with the masses and serving the people's channels and means, timely release of authoritative information, and actively respond to social concerns, and constantly improve the government work", to promote the "Party and government organs and leading cadres to actively use the micro blog". Government micro blog is an important innovation of traditional government processes, the national government into the forefront of public opinion and public opinion, government micro blog is a new product of the development of the micro era, the major national events and the issues of people concerned about in a small amount of information released. How to make good use of micro bog new media to enhance the image of the service-oriented government, to promote the further development of democratic politics, this is a new topic, which is network age given government research. This paper aims to analyzing the current development status of government micro blog, to explore the existing problems in the development process, to help the government to make good use micro blog platform to provide a reference. 


\section{Analysis on Development Status}

Government micro blog is a product of the combination of government communication and micro blog, in order to fully understand the development trend and research situation of government micro blog, through access to books, Internet search and government micro blogging and bloggers' exchange, to collect a series of related books, journals and Internet articles. Be analyzed from two aspects of foreign and domestic.

\section{(1) Foreign Status}

The world's first micro blog pioneer is the US blog technical experts Evan Williams, in which the creation of the Obvious Company launched Twitter. Since Twitter was founded to the present, it has developed into the world's largest number of users, the most widely-ranging, most influential micro blog application platform. Because of the special political and economic forms, the concept of government micro blog only exists in China. Foreign studies are usually concentrated communication management in the public domain, or aspects of the relationship between the public sector and media processing. The earliest exploration of the relationship between the public and the media originated from the political propaganda of the war. These studies gave birth to the communication on the one hand, on the other hand to deepen the knowledge about the relationship between media and political communication. With the gradual popularization of information technology in western countries, e-government has penetrated into all areas of administration, forming a trend of "network governance", has become a political concern public communication platform. Micro blog as one of the most popular interactive communication platform, not only by the welcome of the people, some government officials have opened a micro-blog interactive dialogue with the masses, many heads of state have begun to exchange on the micro-blog. Micro blog in politics has become a new way to network governance.

About foreign research on micro blog, most focused on the functional analysis level, concern social communication functions and personal expression functions. About government micro blog, Britain had within the government on the release of the "government departments Twitter use guide", to regulate the development of the British government micro blog played a role in promoting and improving the use performance aspects of government micro blog has a good reference role, but also provide a reference for all levels of government to carry out government micro blog. The United States is more extensive use of government micro blog countries, in order to create a simple and efficient government, with special emphasis on the use of information technology to reform the government, for the people to build a platform for dialogue and communication with the government, to maximize access to services provided by the government. Currently, the US local, state and federal government departments at all levels to use different kinds of social media, such as processing service requests, holding real-time official interviews, public policy cluster opinions. In summary, the US government micro blog mainly exercises the release policy information, share ideas with the public, as a public diplomacy tool, to prevent and deal with crisis functions. Foreign research mainly focus on three aspects, from the perspective of information dissemination path and technology to explore the reasons for the positive impact of the micro blog, foreign government agencies or officials using the micro blog situation, to explore the role of Twitter in the event of sudden crisis [1,2].

\section{(2) Domestic Status}

Domestic scholars pay attention to the development status and trends of government micro blog, as well as existing problems in the development process. From the perspective of academic context, the existing research involves many aspects, including the communication science, sociology, political science, public policy, public management, public relations and other disciplines. Although extensive research perspective, but in terms of the existing research results, most of them are macroscopic, outlining article, with respect to a perspective more systematic study is relatively small, especially for a case study, the results of regional studies less. From the academic research level, although the existing research has been involved in the concept definition of micro blog, the existing problems of micro blog development, the characteristics and functions of government 
micro blog, the communication effect of government micro blog, the government micro blog to government image building and dissemination role and other related issues, but in the media society, The development of social media is rapidly changing, government micro blog development and the impact on public life is profound, The research of government micro blog is still in its infancy [3]. Specific studies on government micro blog can be divided into three aspects: the connotation of government micro blog, government micro blog research under the care of communication, government micro blog public domain constructed research.

The status quo of the application of government micro blog has three characteristics [4]: First, the number rose sharply, government micro blog has become an important part of public opinion field. Since the establishment of sina, Tencent, the people's daily and other micro blog platform, "safe Beijing" as the representative of the country public security micro blog, as well as all levels of party and government leaders have sprung open micro blog; second is to expand the open scope and areas, the government micro blog by development of a spark to start a prairie fire. Various regions, various government departments most have opened micro blog; third, t the government micro blog group have appeared, government micro blog development by the individual combat to the joint office. The opening of government micro blog group is a breakthrough innovation in the new situation of network politics, to explore a new mass line of the network era; fourth, the increasing maturity of the operation of government micro blog, micro blog politics level continues to increase. The operation process of government micro blog is the process of deepening the network of political work under the new situation at all levels of government. In the process of exploring the micro blog operation, many government departments and officials gained practical experience, the increasing maturity of the operation of government micro blog, micro blog asked political level continue to improve.

\section{(3) Status Review}

Western governments have been the government micro blog as a part of the work of the government, and actively explore their understanding and use, although the development of Chinese government micro blog started later in Britain and the United States and other developed countries, but the rapid pace of development. Micro blog in e-government shows strong vitality, there are also chaotic management and other issues, the need to guide rational and scientific management, in order to fulfill its huge potential [5]. In recent years, domestic academic research on the growing concern of government micro blog, a growing number of scholars recognize that government micro blog has a powerful effect of public opinion, sustained and healthy development related to social harmony and stability, through analysis pointed out the existing problems of the current Chinese government micro blog development. Some scholars put forward positive suggestions for the sustainable and healthy development of China's government micro blog. The current study also is shortcomings: first, most of the literature is the national government micro blog development situation analysis, but the in-depth research is less on the development of government micro blog in a single city or model; second, the majority of the literature is to improve the daily supervision of government micro blog system to study the countermeasures, little mention of government micro blog in response to emergencies in the emergency system construction; third, the majority of the literature on the actual use of government micro blog lack of in-depth understanding, and easy to misleading readers.

\section{Analysis on Existing Problems}

Government micro blog is a product of the era of network governance, micro blog is a kind of productivity, and has led to the formation of the new upper level government. Government micro blog play its smooth character, scene, efficiency and affinity, etc. but also revealed a series of problems, which restricts the road forward of China's network democracy development. At present, China government micro blog in ideas, operation and maintenance, language style, building mechanism, blog certification, the five aspects still faces many problems, combined with previous results [5-10], are summarized as follows: 
(1) The function and position of government micro blog is not clear. Currently open government micro blog government agencies and public officials in a spontaneous state, the general nature of the work and the level of computer applications and the staff of the department are closely related. At present, the government and the academic community on government micro blog did not give a unified definition, in particular, location and function between the party and government agencies micro blog and party and government cadres micro blog is unclear, each micro blog site to define the scope of government micro blog also exist differences, particularly for government micro blog real name certification process for public servants micro blog, there is a certain vulnerability. Public awareness of government micro blog is also in an ambiguous state, although there are many party and government cadres micro blog is a good complement to government agencies micro blog, and at this stage, but also to solve some practical problems, but from the long-term development perspective, if not standardized the use of Party and government departments, easy to make people confused the party and government cadres personal behavior and job behavior, have a negative impact on government management.

(2) The government micro blog regulatory and organizational security missing. The future development of government micro blog is uncertain, how to publish information, publishing what, how to answer users, guide public opinion and so the lack of institutional norms. Micro blog management conflicts of interest to shirk responsibility, departments linkage mechanism is not smooth, lack of investment, lack of talent plaque, running system is not standardized, performance evaluation and other factors, make government micro blog not be a good majority of Internet users to provide timely, reliable service. In addition, because there are no clear rules and regulations and evaluation review mechanism, given the large number of false information on the micro blog, but also verbal attacks on the government, which grasp the micro blog public opinion discourse, the dominant power, the maintenance of order and micro blog politics network information security has brought new risks. In short, in order to promote long-term development of government micro blog, we must clear the fundamental institutional mechanisms, while providing a strong organizational guarantee.

(3) The active degree and the degree of interaction of government micro blog are low. Micro blog greatest charm lies in government officials and government agencies can direct dialogue with the public, to achieve the spread of democratization ways. However, due to government micro blog in a disordered state, and lack of relevant regulations and rules, the overall level of activity is not high, and the degree of interaction with the public is relatively low. Should strengthen the mechanism of government micro blog, interactive, timely response to the concerns of Internet users, to enhance the reliability of Internet users on government micro blog, improve the utilization of government micro blog. An important aspect of government micro blog construction mechanism is the introduction of the relevant management regulations of government micro blog, clear chief responsible person of the department of government micro blog, information released specific person, information browsing and collect the person in charge, as well as the relationship between the three. Information release time, the response time to receive user's demands, it must have a clear responsibility, but also have the clear punitive measures.

(4) Government micro blog development lack of long-term maintenance of power. The political participation of citizens in government micro blog approximate "Praetorian" type has led to the government's pressure accumulation, support and requires long-term imbalances, gradually led to the government micro blog maintenance power dissipation; under the current social background that livelihood politics has become the mainstream discourse, citizens can express through the micro blog directly to the government's own reasonable expectations and forcing the government to face this demand to make the corresponding response, leading to government micro blog function overloading, resulting in the government's "blog deficit Micro" pressure; from the government point of view, the government micro blog is more popular with macro social management system innovation natural extension. If the government micro blog too much emphasis on the nature of social governance in the dimension of technology, while ignoring the intrinsic conjunction and 
democratic politics in value dimensions, after all, will inevitably become form and specious, as a means of technology governance may be not long.

(5) Government micro blog lack the necessary marketing tool. The consequence of the lack of marketing concept is the government micro blog number of fans and the insufficient number of the concern object, the number of posts is insufficient. Number of posts includes original post, transfer and evaluation of posts and other posts. Insufficient number of posts will be a direct result of not timely updates, lack of information, not only does not attract more attention to micro blog users become fans of government micro blog, and users have become their fans and also because there is no new content no concern, causing fans have been natural loss wastage. Some people think that government micro blog set up by specific features of government, as if there is no need to pay attention to other users, this understanding is completely wrong. Government micro blog only full attention of others, can timely know another micro blog users post content, which is a good way to collect the concern object information, which is also an understanding of the people, listen to voice of the people, close party, government relations group ties and bridges.

(6) Development region and application domain of government micro blog imbalance. From the distribution of the administrative level of party and government agencies and officials to view, the opening of government micro blog in the number of exhibits pyramid type distribution, grassroots party and government agency officials to open more. Grassroots staff the more opportunity to work usually contact with the masses, opening government micro blog consciousness is relatively strong. The higher level of Party and government officials, usually contact with the people less, the opening of government micro blog awareness is weak. From the perspective of the opening of the party and government micro blog, the number of huge difference, the regional division is more serious, the number of central and western regions is significantly less. From the department of government micro blog development, the opening up to the public security system, followed by the Communist Youth League and the propaganda system. People are very concerned about the traffic and medical, and others, the proportion of these are less, indicating that these departments service awareness is weak. The process of government micro blog development appear unbalanced phenomenon, is not conducive to its steady, coordinated and healthy development. For this stage, the ongoing reform of socialist democratic politics is extremely unfavorable.

(7) Content and form of the government micro blog is inflexible. The content of government micro blog post information, formal official sample, not really starting from the demands of the masses, resulting in relation to the public their own interests, to facilitate the public directly interpret and use the information inadequate. Currently most government micro blog, throughout the document like information release, content in the form of a single, released information program stiff, hard to attract the attention of Internet users. Although some government departments launched micro blog, but not to publish any information, or rely on a few government announcement forwarding, local news, information update frequency is slow, become in name only "zombie micro blog". There are some government departments, even though it can adhere to update, but throughout all the boring news bulletins or government policy, contents and forms does not carry on the innovation. These will lead to great dissatisfaction of Internet users, resulting in rupture of government friendly image.

\section{Conclusion}

Government micro blog as an emerging tool of network politic, is a bridge the government actively communicate with the people, interact with the people. To better serve the people is the purpose of the reform of government functions, but also to create the essential requirements of service-oriented government. Active use of government micro blog is the best embodiment of people-oriented governing philosophy. Strengthen the government micro blog management regulations help to ensure government micro blog utility maximization, and the negative impacts and potential risks to a minimum. To fully understand the current development status of government micro blog and solve the existing problems, the government micro blog management penetrates to the real work of government. Governments should take full advantage of the emerging media government micro 
blog, and constantly improve the public affairs, government affairs and public systems in various fields, to accept supervision by the masses, make socialist democratic politics show a more exuberant vitality.

\section{Acknowledgement}

This work is supported by social science fund project of Liaoning province (L13BGL013): Research on management practice and development strategy of government microblogging in Liaoning province.

\section{References}

[1] H. Wang, "The development and trend of China's government," Master's degree of Shenyang Normal University, 2014.

[2] Y. W. Zhang, "Research summary on government micro blog development," The Science of Leadership Forum, vol. 26, no. 12, pp. 17-18, 2013.

[3] W. W. Zhang, " Henan Government Micro-blog Research: Based on the Communication Perspective of Public Policy," Master's degree of Henan University, 2014.

[4] R. Liu, G. Y. Xie, "Status quo, problems and countermeasures on China government microblogging operation," Editorial Friend, vol. 27, no. 7, pp. 10-14, 2012.

[5] X. Mao, "Study on confronting problems in the development of government affairs microblog and corresponding countermeasures," Master's degree of Southwestern University, 2014.

[6] Y. M. Wang, Y. Ding, H. M. Hu, "Status quo and countermeasures on development of government micro blog in China," Administration Reform, vol. 4, no. 10, pp. 71-75, 2012.

[7] X. N. Li, W. Q. Chen, "Research summary on development status and theory for China government micro blog," The Journal of Yunnan Administration College, vol. 17, no. 4, pp. 89-93, 2014.

[8] R. L. Yang, "Research on the current situation and strategy of government micro Blog Communication: Based on the empirical analysis of Yunnan Province," News Research, vol. 30, no. 6, pp. 9-11, 2013.

[9] J. M. Cao, "Effect on government micro blog in the construction of public relations," The Press, vol. 60, no. 11, pp. 103-105, 2015.

[10] H. Wang, "The present situation and thinking of the development of government micro blog in Kunming," Journal of News Research, vol. 6, no. 3, pp. 98-99, 2015. 